OPEN ACCESS

Edited by:

Joshua D. Nosanchuk, Albert Einstein College of Medicine,

Reviewed by:

Gyöngyvér Mara,

Sapientia Hungarian University of Transylvania, Romania

Huafeng Wang,

University of Wisconsin-Madison,

USA

*Correspondence:

Qiyong Weng

wengqy@faas.cn

Qinghe Chen

chenqh@faas.cn

Specialty section:

This article was submitted to

Fungi and Their Interactions,

a section of the journal

Frontiers in Microbiology

Received: 17 May 2016

Accepted: 25 July 2016

Published: 04 August 2016

Citation:

Liu $P$, Gong J, Ding $X$, Jiang $Y$, Chen $G, L i B$, Weng $Q$ and Chen $Q$

(2016) The L-type $\mathrm{Ca}^{2+}$ Channel Blocker Nifedipine Inhibits Mycelial Growth, Sporulation, and Virulence

of Phytophthora capsici.

Front. Microbiol. 7:1236.

doi: 10.3389/fmicb.2016.01236

\section{The L-type $\mathrm{Ca}^{2+}$ Channel Blocker Nifedipine Inhibits Mycelial Growth, Sporulation, and Virulence of Phytophthora capsici}

\author{
Peiqing Liu, Jie Gong, Xueling Ding, Yue Jiang, Guoliang Chen, Benjin Li, Qiyong Weng* \\ and Qinghe Chen*
}

Fujian Key Laboratory for Monitoring and Integrated Management of Crop Pests, Institute of Plant Protection, Fujian

Academy of Agricultural Sciences, Fuzhou, China

The oomycete vegetable pathogen Phytophthora capsici causes significant losses of important vegetable crops worldwide. Calcium and other plant nutrients have been used in disease management of oomycete pathogens. Calcium homeostasis and signaling is essential for numerous biological processes, and $\mathrm{Ca}^{2+}$ channel blockers prevent excessive $\mathrm{Ca}^{2+}$ influx into the fungal cell. However, it is not known whether voltagegated $\mathrm{Ca}^{2+}$ channel blockers improve control over oomycete pathogens. In the present study, we compared the inhibitory effects of $\mathrm{CaCl}_{2}$ and the extracellular $\mathrm{Ca}^{2+}$ chelator EDTA on mycelial growth and found that calcium assimilation plays a key role in $P$. capsici mycelial growth. Next, we involved the voltage-gated $\mathrm{Ca}^{2+}$ channel blockers verapamil (VP) and nifedipine (NFD) to analyze the effect of $\mathrm{Ca}^{2+}$ channel blockers on mycelial growth and sporulation; the results suggested that NFD, but not VP, caused significant inhibition. Ion rescue in an NFD-induced inhibition assay suggested that NFD-induced inhibition is calcium-dependent. In addition, NFD increased $P$. capsici sensitivity to $\mathrm{H}_{2} \mathrm{O}_{2}$ in a calcium-dependent manner, and extracellular calcium rescued it. Furthermore, NFD inhibited the virulence and gene expression related to its pathogenicity. These results suggest that NFD inhibits mycelial growth, sporulation, and virulence of $P$. capsici.

Keywords: Phytophthora capsici, nifedipine, calcium rescue, virulence, $\mathrm{H}_{2} \mathrm{O}_{2}$

\section{INTRODUCTION}

Calcium acts as a second messenger and plays a direct role in controlling the expression patterns of its signaling systems in fungi. It is essential for numerous intrinsic metabolic processes including spore germination, hypha tip growth and branching, sporulation, hypha infection structure differentiation, circadian clocks, and responses to various environmental stresses (Liu et al., 2015a). However, improper regulation of $\mathrm{Ca}^{2+}$ in fungi can produce significant damages and even ultimately lead to cell death (Hu et al., 2013; Gonçalves et al., 2014; Liu et al., 2015b). Normally, calcium channels allow the passive flow of $\mathrm{Ca}^{2+}$ across cell membranes into the cytosol. Two major calcium uptake pathways have been identified in Saccharomyces and other fungi: the high-affinity (HACS) and low-affinity (LACS) calcium uptake systems (Martin et al., 2011; Wang et al., 2012; Harren and Tudzynski, 2013). The Cch1 and Mid1 $\mathrm{Ca}^{2+}$ channel complex constitutes the HACS (Cch1 functions as the pore, and Mid1 serves as a assistance) that mediates 
the specific influx of $\mathrm{Ca}^{2+}$ (Cavinder et al., 2011; Harren and Tudzynski, 2013). Mid1 and Cch1 have been identified in many filamentous fungi (Hallen and Trail, 2008; Yu et al., 2012), and deletion of Mid1 affects vegetative growth, cell wall synthesis, and virulence in Claviceps purpurea (Bormann and Tudzynski, 2009). In Botrytis cinerea, Cch1 and Mid1 are functionally required for vegetative growth under low-calcium conditions (Harren and Tudzynski, 2013). In Gibberella zeae, Mid1 affects the hypha growth, development processes, and even ascospore discharge significantly (Cavinder et al., 2011). In Cryptococcus neoformans, knock-out of Mid1 or Cch1 can caused significantly inhibition to oxidative stress (Vu et al., 2015).

In fact, voltage-gated $\mathrm{Ca}^{2+}$ channel blockers function in various modes. VP, one of the important L-type calcium channel blocker, is widely used in the medical treatment and served as a miracle drug in the treatment of angina pectoris and even hypertension. It partially inhibits the function of HACS, resulting in decreased calcium influx under normal growth conditions in S. cerevisiae and Candida albicans (Breeuwer et al., 1995; Yu et al., 2014). Nifedipine (NFD), used as a dihydropyridine derivative commonly, forms a stable complex with the L-type calcium receptors binding site, which is made up of six spatially separated amino acid residues while its conformation corresponds to the closed channel. NFD preferentially blocks $\mathrm{Ca}^{2+}$ channels of various cell types and prevents $\mathrm{Ca}^{2+}$ influx by reducing cytosolic $\mathrm{Ca}^{2+}$ concentrations (Nguemo et al., 2013). Diltiazem, a benzothiazepine-type calcium channel blocker, blocks L-type calcium channel by way of their high-affinity binding (Hockerman et al., 2000). The voltage-gated $\mathrm{Ca}^{2+}$ channel blockers can be used to treat the fungal pathogen $C$. albicans (Yu et al., 2014), and diltiazem and VP can block the opening of voltage-gated L-type $\mathrm{Ca}^{2+}$ channels and prevent a severe $\mathrm{Ca}^{2+}$ influx into the animal cells and S. cerevisiae (Teng et al., 2008). High concentrations of diltiazem also resulted in enhanced $\mathrm{Ca}^{2+}$ accumulation in S. cerevisiae cells (Binder et al., 2010). In addition, chelating extracellular calcium modulates cytosolic calcium, which severely reduces the expression of several calcium transport proteins and influences the normal functions of fungi (Juvvadi et al., 2015; Puigpinós et al., 2015). The reduction of intracellular calcium is responsible for the inhibition of reactive oxygen species (ROS)-generating enzymes and formation of free radicals by the mitochondria respiratory chain (Gordeeva et al., 2003; Kraus and Heitman, 2003). The Cch1-Mid1 regulated HACS contributes to a virulence change in C. neoformans by mitigating oxidative stress (Vu et al., 2015), and VP has an inhibitory effect on the oxidative stress response in C. albicans (Yu et al., 2014), confirming the relationship between calcium signaling and oxidative stress.

The oomycete vegetable pathogen $P$. capsici is a virulent, hemibiotrophic pathogen of vegetable crops, which inflicts significant losses of important vegetable crops worldwide (Jackson et al., 2012). Although it was first described almost 90 years ago, no direct and effective managements have been developed (Lamour et al., 2012). P. capsici has shown remarkable adaptation to fungicides and new hosts. Cinnamaldehyde (CA) is a major constituent of cinnamon essential oils and has been used as a food antimicrobial agent for its inhibiting of bacteria, yeast, and filamentous fungus, which involves membrane action, cell wall synthesis, and specific cellular processes (Wang et al., 2005; Shreaz et al., 2010). Previous studies also have shown that calcium efflux is involved in CA-induced inhibition of $P$. capsici zoospores (Hu et al., 2013). In addition, treatment with the voltage-gated calcium channel blocker verapamil (VP) can lead to a higher level of CA-induced $\mathrm{Ca}^{2+}$ efflux, suggesting that the $\mathrm{Ca}^{2+}$ channel may be a target for controlling pathogens. Furthermore, plant nutrients, especially $\mathrm{Ca}^{2+}$, can be applied to the disease management in Phytophthora spp. (Sugimoto et al., 2005), and more attention has focused on the suppressive effect of calcium on Phytophthora spp. (Sugimoto et al., 2010). In fact, $\mathrm{CaCl}_{2}$ and $\mathrm{Ca}\left(\mathrm{NO}_{3}\right)_{2}$ can dramatically suppress disease incidence caused by $P$. sojae in black soybean and white soybean and affect plant resistance. Moreover, $4-30 \mathrm{mM} \mathrm{CaCl}_{2}$ and $\mathrm{Ca}\left(\mathrm{NO}_{3}\right)_{2}$ can decrease the release of $P$. sojae zoospores (Sugimoto et al., 2005). Although voltage-gated $\mathrm{Ca}^{2+}$ channel blockers have been used widely, it is not known whether they could be used to control oomycete pathogens, especially $P$. capsici. In the present study, we investigated the effects of voltage-gated $\mathrm{Ca}^{2+}$ channel blockers on P. capsici mycelial growth, sporulation, and virulence.

\section{MATERIALS AND METHODS}

\section{Phytophthora capsici Strains and Culture Conditions}

The $P$. capsici genome-sequenced virulence strain LT1534 was provided by Prof. Lamour (University of Tennessee, Knoxville, TN, USA), which has been used as a model strain by more and more scientists (Stam et al., 2013; Iribarren et al., 2015; Liu et al., 2016). Strain LT1534 was grown on 10\% V8 juice agar medium at $25^{\circ} \mathrm{C}$ in the dark (Lamour et al., 2012). Radial growth was measured at day 5 , when the colony of the strain LT1534 had almost completely covered the surface of the media in the dishes. Radial growth was assessed by measuring the distance from the edge of the inoculum plug to the advancing margin of the colony.

\section{Effect of $\mathrm{CaCl}_{2}$ and EDTA on Mycelial Growth of $P$. capsici}

To test the inhibitory effect of $\mathrm{CaCl}_{2}$ and the extracellular $\mathrm{Ca}^{2+}$ chelator EDTA on P. capsici mycelial growth, strain LT1534 was grown on $10 \% \mathrm{~V} 8$ juice agar medium at $25^{\circ} \mathrm{C}$, and then 1-weekold agar plugs ( $5 \mathrm{~mm}$ diameter) transferred onto the center of dish (10\% V8 juice agar medium containing $0,2.5,5,10,25$, and $50 \mathrm{mM} \mathrm{CaCl}_{2}$, and $0,0.5,1.0,2.5,5$, and $10 \mathrm{mM} \mathrm{EDTA).}$ Radial growth was measured at day 5 . Stock solutions of $\mathrm{CaCl}_{2}$ and EDTA were prepared as $1 \mathrm{M} \mathrm{CaCl}_{2}$ in $\mathrm{H}_{2} \mathrm{O}$ (Sigma-Aldrich) and $1 \mathrm{M}$ EDTA in $\mathrm{H}_{2} \mathrm{O}$ (Sigma-Aldrich).

\section{Effect of VP and NFD on Mycelial Growth and Sporulation}

To analyze the growth inhibitory effect of VP and NFD on P. capsici strain LT1534, $0,10,40,80,160$, and $320 \mu \mathrm{g} / \mathrm{mL} \mathrm{VP}$ 
and $0.1,0.2,0.5,1$, and $2 \mu \mathrm{M}$ NFD were added to $10 \% \mathrm{~V} 8$ juice agar medium, and radial growth was measured at day 5 . Stock solutions of VP and NFD were prepared as $320 \mathrm{mg} / \mathrm{mL}$ $\mathrm{VP}$ in $\mathrm{H}_{2} \mathrm{O}$ (Sigma-Aldrich) and $50 \mathrm{mM}$ NFD in DMSO (SigmaAldrich).

To analyze zoosporangia density, the mycelia were washed three times with $30 \mathrm{~mL}$ of sterile distilled water and then an additional $20 \mathrm{~mL}$ of sterile distilled water was added to induce sporangia formation in the dark at $25^{\circ} \mathrm{C}$ for $24 \mathrm{~h}$. The number of zoosporangia was counted and the mean of three duplications was used as the result of one replicate. Each experiment was repeated in triplicate wells at least three times.

To investigate whether calcium is associated with the inhibitory effect of NFD, strain LT1534 was grown on $10 \%$ V8 juice agar medium at $25^{\circ} \mathrm{C}$, and then 1-week-old agar plugs (5 $\mathrm{mm}$ diameter) transferred onto the center of dish (10\% V8 juice agar medium containing $0.5 \mu \mathrm{M}$ NFD (Control), $0.5 \mu \mathrm{M}$ $\mathrm{NFD}+20 \mathrm{mM} \mathrm{CaCl} 2,0.5 \mu \mathrm{M} \mathrm{NFD}+50 \mathrm{mM} \mathrm{CaCl}_{2}, 0.5 \mu \mathrm{M}$ $\mathrm{NFD}+20 \mathrm{mM} \mathrm{KCl}$, and $0.5 \mu \mathrm{M} \mathrm{NFD}+20 \mathrm{mM} \mathrm{NaCl})$. Radial growth was measured at day 5 .

\section{Determination of Cytosolic Free $\mathrm{Ca}^{2+}$ Levels by Using the Probe Fluo-3-AM}

$P$. capsici strain LT1534 was cultured for 2-3 days on the $10 \%$ V8 juice agar medium containing $0.5 \mu \mathrm{M}$ NFD. Fluo-3-AM was prepared from a $1 \mathrm{mM}$ stock solution in DMSO (Sigma) and added to the small pieces $(1 \mathrm{~cm} \times 1 \mathrm{~cm})$ of $P$. capsici to a final concentration of $150 \mu \mathrm{M}$. The cultures were incubated at $37^{\circ} \mathrm{C}$ for $1 \mathrm{~h}$ for dye loading. Images of calcium green fluorescence were observed under a Nikon microscope by using a 450 - to $490-\mathrm{nm}$ excitation filter and a 520-nm barrier filter.

\section{Sensitivity Test to Oxidative Stress during NFD Treatment}

To test the sensitivity of mycelial growth to oxidative stress, strain LT1534 was grown on $10 \%$ V8 juice agar medium at $25^{\circ} \mathrm{C}$, and then $\mathrm{H}_{2} \mathrm{O}_{2}$ was added onto $10 \% \mathrm{~V} 8$ juice agar medium at final concentrations of $0,1.25,2.5,5$, and $10 \mathrm{mM}$. To investigate the effect of NFD on $P$. capsici mycelial growth under $\mathrm{H}_{2} \mathrm{O}_{2}$, radial growth was measured at $25^{\circ} \mathrm{C}$ for 5 days in V8 medium containing $0.5 \mu \mathrm{M} \mathrm{NFD}, 5 \mathrm{mM} \mathrm{H}_{2} \mathrm{O}_{2}, 20 \mathrm{mM} \mathrm{CaCl}_{2}$, $0.5 \mu \mathrm{M} \mathrm{NFD}+1.25 \mathrm{mM} \mathrm{H}_{2} \mathrm{O}_{2}, 0.5 \mu \mathrm{M} \mathrm{NFD}+2.5 \mathrm{mM} \mathrm{H}_{2} \mathrm{O}_{2}$, $0.5 \mu \mathrm{M} N F D+5 \mathrm{mM} \mathrm{H}_{2} \mathrm{O}_{2}, 0.5 \mu \mathrm{M} \mathrm{NFD}+10 \mathrm{mM} \mathrm{H}_{2} \mathrm{O}_{2}, 0.5 \mu \mathrm{M}$ $\mathrm{NFD}+10 \mathrm{mM} \mathrm{H}_{2} \mathrm{O}_{2}+20 \mathrm{mM} \mathrm{CaCl}_{2}$, and $0.5 \mu \mathrm{M} \mathrm{NFD}+10 \mathrm{mM}$ $\mathrm{H}_{2} \mathrm{O}_{2}+50 \mathrm{mM} \mathrm{CaCl}_{2}$.

\section{Virulence Test}

Zoospores were induced from 5 -day-old sporangia by washing with sterile distilled water for $24 \mathrm{~h}$ at $25^{\circ} \mathrm{C}$, and then harvested by centrifugation at $3000 \times g$ for $5 \mathrm{~min}$. The number of zoospores in $10 \mu \mathrm{L}$ of zoospore suspension was counted using a blood cell counting chamber. Pepper cultivars (Capsicum annuum L. cv. yanshan01, CM334, and ECW) were collected from Yunnan province, China (Liu et al., 2015b) and grown in plastic pots containing vermiculite at $25^{\circ} \mathrm{C}$ for 4 days in the dark. The hypocotyls of etiolated seedlings were inoculated with 100 zoospores, and then etiolated seedlings were maintained in $80 \%$ humidity and darkness at $25^{\circ} \mathrm{C}$. The pathogenicity results were investigated and photographs were taken 3 days post-inoculation (dpi).

\section{RNA Extraction and Quantitative Reverse Transcription Polymerase Chain Reaction (qRT-PCR)}

Total RNA of mycelia was extracted using an RNA kit (Tiangen, China), and cDNA was generated according to the protocol of the PrimeScript RT reagent kit (TaKaRa). qRT-PCR assays were performed using the primers shown in Table $\mathbf{1}$ and carried out in a BioRad CFX96 Real-Time PCR Detection instrument (Bio-Rad Laboratories) using standard PCR conditions. To confirm product specificity, we performed a melting curve analysis. Normally, a $20-\mu \mathrm{L}$ reaction volume contained $2 \mu \mathrm{L}$ of reverse transcription product, $10 \mu \mathrm{L}$ of SYBR real-time PCR mix $(2 \mathrm{x})$, and $0.4 \mu \mathrm{L}$ of each primer $(10 \mu \mathrm{M})$. The $P$. capsici internal transcribed spacer (ITS) region was used as a constitutively expressed endogenous control, and the expression of each gene in Table 1 was determined relative to the $P$. capsici ITS region using the $\Delta \Delta C$ t method. qRT-PCR experiments were repeated in triplicate with independent RNA isolations.

\section{Statistical Analysis}

All measurements were conducted at least three times. Data were analyzed by one-way analysis of variance (ANOVA) using SPSS software version 19.0 (IBM) and mean comparison was conducted by a Dunnett's test. Different letters above bars indicate statistical differences $\left({ }^{* *} P<0.01\right.$ and $\left.{ }^{*} P<0.05\right)$.

\section{RESULTS}

\section{Effect of Calcium on P. capsici Mycelial Growth}

Plant nutrients are often used in disease management, and the application of $\mathrm{CaCl}_{2}$ dramatically suppresses disease incidence caused by $P$. sojae in soybean under laboratory conditions and in field applications (Sugimoto et al., 2005). In the present study, we analyzed the effects of $\mathrm{CaCl}_{2}(0,2.5,5.0,10,25$, and $50 \mathrm{mM})$ and the extracellular $\mathrm{Ca}^{2+}$ chelator EDTA $(0,0.5,1.0,2.5,5.0$, and $10 \mathrm{mM}$ ) on $P$. capsici virulence strain LT 1534 mycelial growth. In our results, $2.5 \mathrm{mM} \mathrm{CaCl}$ increased mycelial growth; however,

TABLE 1 | Sequences of primers used in the present study.

\begin{tabular}{ll}
\hline Gene & Primer sequence $\left(\mathbf{5}^{\prime} \mathbf{-} \mathbf{3}^{\prime} \mathbf{)}\right.$ \\
\hline P. capsici ITS region & Forward: GTATAGCAGAGGTTAGTGAA \\
PCLAC2 & Reverse: GACGTTTAGTTAGAGCACTG \\
& Forward: CTCATCAACTCAGTCACA \\
PCPL16 & Reverse: GGTTCTGCTTGGAATAG \\
& Forward: CCGACCTTGTCACTTATG \\
& Reverse: TGTTGTGATTCCGAGAG
\end{tabular}


A

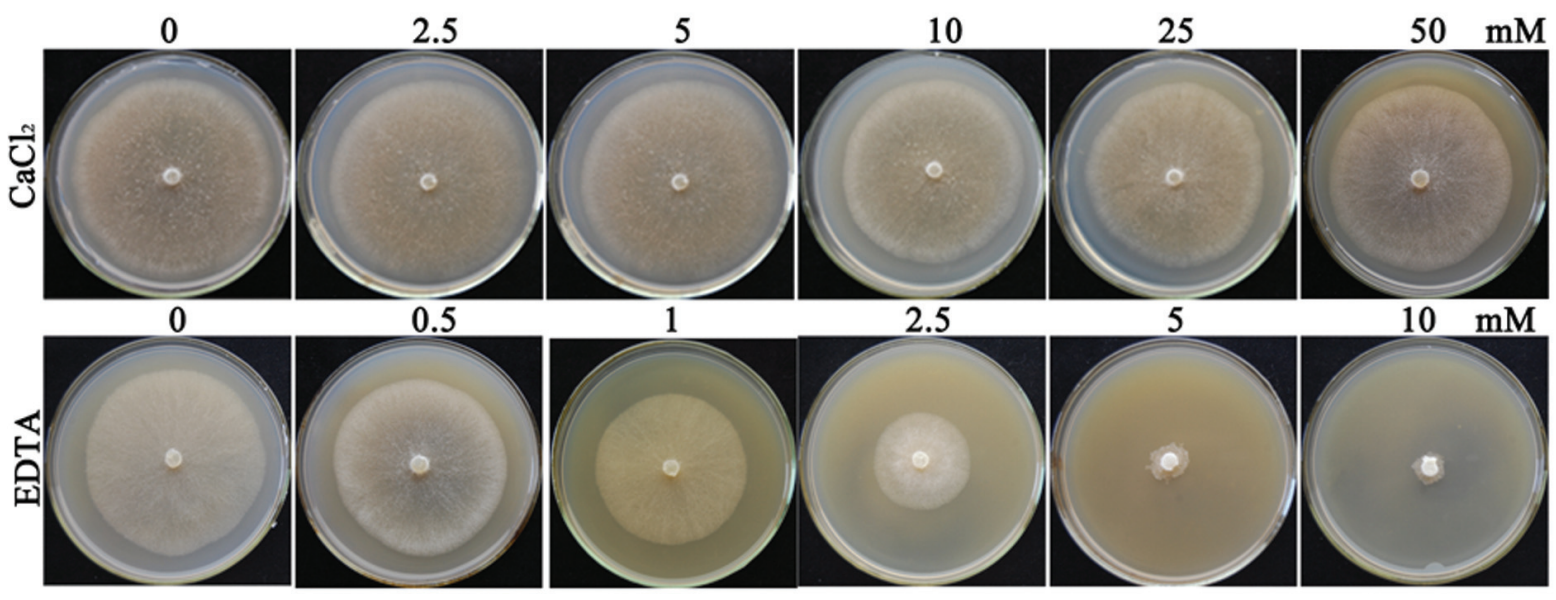

B

C
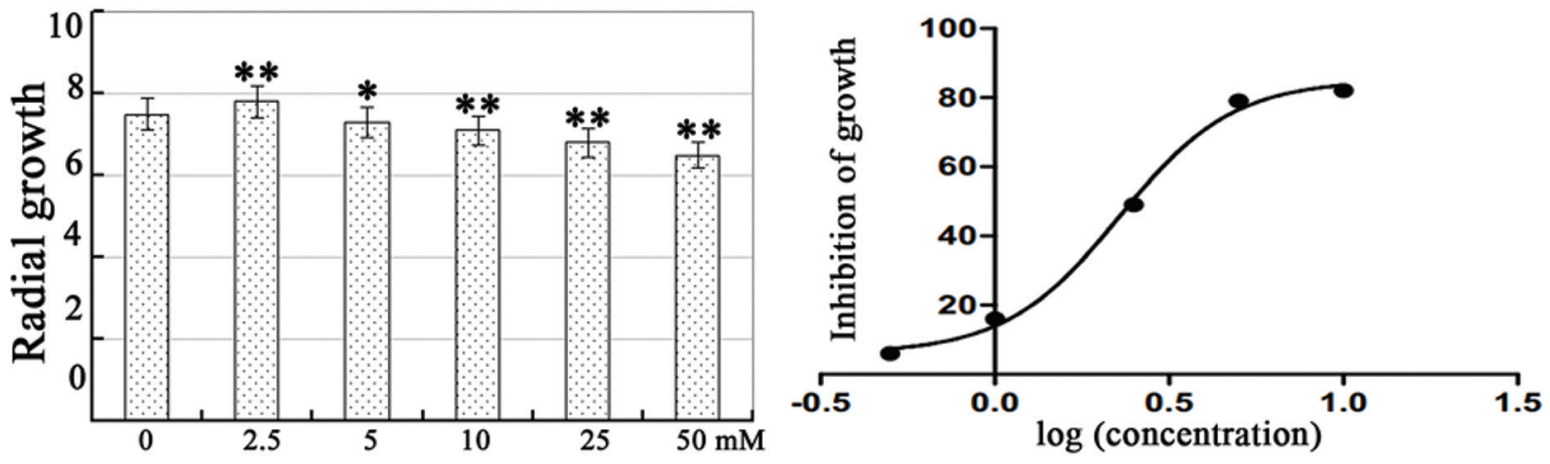

FIGURE 1 | Effect of $\mathrm{CaCl}_{2}$ and EDTA on mycelial growth of Phytophthora capsici. (A) P. capsici cultures in Petri dishes illustrating the inhibition of mycelial radial growth with increasing $\mathrm{CaCl}_{2}$ and EDTA concentrations. The mycelial colonies were 5 days old and radial growth (mm) was assessed by measuring the distance from the edge of the inoculum plug to the advancing margin of the colony. (B) Statistical analysis of the inhibition of $P$. capsici mycelial growth at various $\mathrm{CaCl}_{2}$ concentrations. (C) Statistical analysis of the inhibition of $P$. capsici mycelial growth at various EDTA concentrations. The assays were repeated three times; $n=5$ for each assay. EC50 is the concentration at which growth is inhibited by $50 \%$. Trend-lines were fitted using a logarithmic function. Different letters above bars indicate statistical differences (** $P<0.01$ and ${ }^{*} P<0.05$, according to Dunnett's test).

growth was inhibited at $5 \mathrm{mM}$, reaching only $13 \%$ growth rate at $50 \mathrm{mM}$. In addition, EDTA reduced mycelial growth significantly and the half maximal effective concentration $\left(\mathrm{EC}_{50}\right)$ value for EDTA-induced inhibition of mycelial growth was $2.5 \mathrm{mM}$ (Figure 1). These results showed that calcium is essential, but higher concentrations are destructive, suggesting that $P$. capsici mycelial growth is regulated by calcium assimilation significantly.

\section{Nfd, But Not Vp, Inhibits $P$. capsici Mycelial Growth and Sporulation Significantly}

Disruption of the genes encoding calcium channels results in abnormal calcium uptake for homeostasis and signaling, and impacts vegetative growth, polarity, cell wall integrity, and virulence (Bormann and Tudzynski, 2009; Wang et al., 2012). We evaluated the inhibitory effect of VP and NFD on mycelial growth and sporulation in P. capsici. As shown in Figure 2, mycelial growth and sporulation were inhibited by VP and NFD compared with the non-treated control. The highest dose of NFD $(2 \mu \mathrm{M})$ inhibited mycelial growth and sporulation by 53 and $100 \%$, but the highest dose of VP $(320 \mu \mathrm{g} / \mathrm{mL})$ only inhibited by 21 and 28\%, suggesting that NFD inhibits mycelial growth and sporulation of $P$. capsici significantly. In addition, NFD led to concentration-dependent inhibition of $P$. capsici mycelial growth and sporulation, which peaked at $2 \mu \mathrm{M}$. Furthermore, NFD showed 30-35\% greater inhibition of mycelial growth and 55-60\% greater inhibition of sporulation. The above results suggest that NFD, but not VP, inhibits $P$. capsici mycelial growth and sporulation significantly. Furthermore, we also evaluated the inhibitory effect of NFD on the intensity of fluorescence emission representing the relative amounts of free intracellular $\mathrm{Ca}^{2+}$. As shown in Figure 3, strong green fluorescence was observed in the control. On the contrast, the fluorescence of NFD treated $P$. capsici decreased notably. These results suggest that NFD regulates the content of cytosolic free $\mathrm{Ca}^{2+}$ levels. 
A

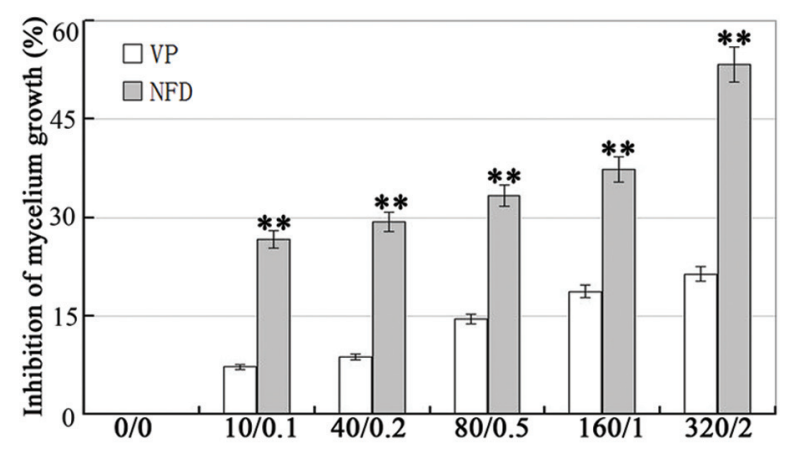

B

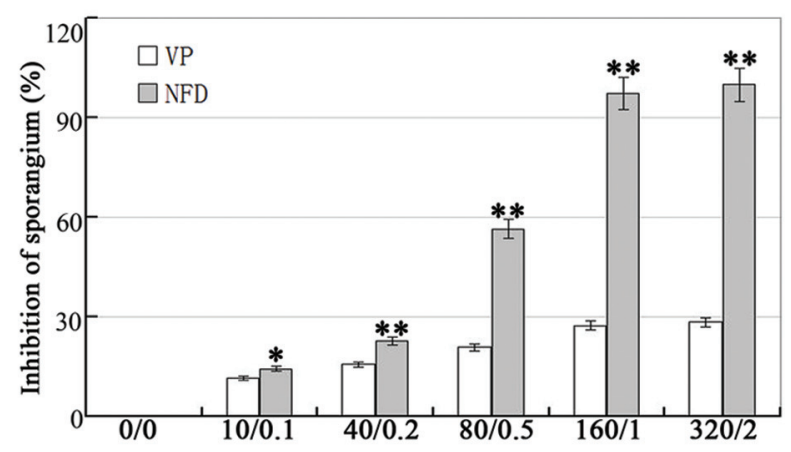

FIGURE 2 | Effects of verapamil (VP) and nifedipine (NFD) on mycelial growth and sporulation of $\boldsymbol{P}$. capsici. (A) Analysis of the inhibition of $P$. capsici mycelium growth at various VP and NFD concentrations. The mycelial colonies were 5 days old and radial growth (mm) was assessed by measuring the distance from the edge of the inoculum plug to the advancing margin of the colony. (B) Analysis of the inhibition of $P$. capsici sporulation at various VP and NFD concentrations. The assays were repeated three times; $n=5$ for each assay. Different letters above bars indicate statistical differences $(* * P<0.01$ and $* P<0.05$, according to Dunnett's test).

\section{Rescue of NFD-Inhibited Mycelial Growth by Extracellular Calcium}

Next, we investigated whether the inhibitory effect of NFD could be rescued by extracellular calcium levels. As shown in Figure 4A, NFD treated alone inhibited mycelial growth by $33.7 \%$ compared with the non-treated control, and NFD+20 $\mathrm{mM} \mathrm{CaCl}_{2}$ did not rescue NFD inhibited mycelial growth. However, the inhibition of mycelial growth in NFD+50 $\mathrm{mM} \mathrm{CaCl}_{2}$ was $19 \%$, suggesting that $50 \mathrm{mM} \mathrm{CaCl}_{2}$ can restrain NFD inhibited mycelial growth and rescue by $14.7 \%$. To exclude non-specific (such as osmotic) effects of $\mathrm{CaCl}_{2}$ due to its high concentrations, other salts (e.g., $\mathrm{NaCl}$ and $\mathrm{KCl}$ ) was employed to investigate the effect of NFD-induced reduction of mycelial growth. Our results showed that $20 \mathrm{mM}$ $\mathrm{NaCl}$ and $\mathrm{KCl}$ do not increase cell growth. These results suggest that NFD-induced inhibition of mycelial growth is calciumdependent.

\section{NFD Increased $P$. capsici Sensitivity to $\mathrm{H}_{2} \mathrm{O}_{2}$ in a Calcium-Dependent Manner}

Adaptation of pathogens to plant-derived ROS is important for their successful infection (Ermak and Davies, 2002; Sheng et al., 2015). In the present study, $0,1.25,2.5,5$, and $10 \mathrm{mM}$ $\mathrm{H}_{2} \mathrm{O}_{2}$ was used to investigate the effect of oxidative stress on $P$. capsici mycelial growth. As shown in Figure $4 \mathbf{B}$, the mycelial growth was significantly inhibited by $55-60 \%$, when treated with $10 \mathrm{mM} \mathrm{H} \mathrm{H}_{2}$. The inhibitory effect of $\mathrm{H}_{2} \mathrm{O}_{2}$ on $P$. capsici mycelial growth was concentration dependent, suggesting that $P$. capsici is sensitive to oxidative stress in an $\mathrm{H}_{2} \mathrm{O}_{2}$ concentration-dependent manner. Furthermore, the effect of NFD on $P$. capsici oxidative stress and whether $0.5 \mu \mathrm{M}$ NFD influenced the sensitivity of $P$. capsici to $\mathrm{H}_{2} \mathrm{O}_{2}$ were analyzed. As shown in Figure 4C, the inhibition of mycelial growth by NFD or $5 \mathrm{mM} \mathrm{H}_{2} \mathrm{O}_{2}$ treatment were 23.1 and $12.3 \%$ compared with the non-treated control, but NFD $+5 \mathrm{mM} \mathrm{H}_{2} \mathrm{O}_{2}$ treatment inhibited mycelial growth by $41.5 \%$. Furthermore, NFD+10 mM $\mathrm{H}_{2} \mathrm{O}_{2}$ treatment inhibited mycelial growth by $57 \%$, suggesting that NFD

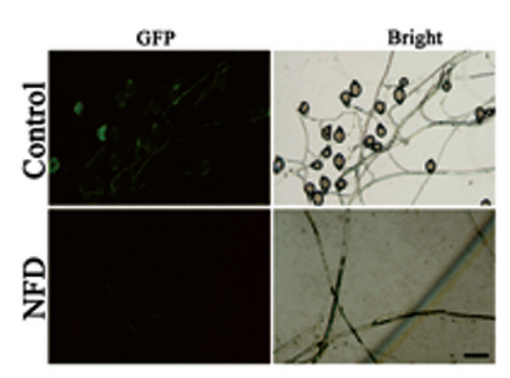

FIGURE 3 | Cytosolic $\mathrm{Ca}^{2+}$ images of $\boldsymbol{P}$. capsici observed by light microscopy and fluorescence microscopy when NFD was added. Fluo-3-AM $(150 \mu \mathrm{M})$ was added to the small pieces $(1 \mathrm{~cm} \times 1 \mathrm{~cm})$ of $P$. capsici. The intensities of green fluorescence represent the relative amounts of free cytosolic $\mathrm{Ca}^{2+}$. Bar $=20 \mu \mathrm{m}$.

increased the sensitivity of $P$. capsici to oxidative stress, which is dependent on the concentration of $\mathrm{H}_{2} \mathrm{O}_{2}$. However, $\mathrm{NFD}+\mathrm{H}_{2} \mathrm{O}_{2}$ $+50 \mathrm{mM} \mathrm{CaCl} 2$ treatment restrained NFD+10 mM $\mathrm{H}_{2} \mathrm{O}_{2}$ inhibited mycelial growth and rescue by $49.2 \%$, suggesting that $50 \mathrm{mM} \mathrm{CaCl} 2$ can rescue the inhibitory effect of NFD+10 $\mathrm{mM}$ $\mathrm{H}_{2} \mathrm{O}_{2}$. Therefore, NFD increased $P$. capsici sensitivity to $\mathrm{H}_{2} \mathrm{O}_{2}$, and extracellular calcium rescued it.

\section{NFD Inhibition of $P$ capsici Virulence and Expression of Genes Involved in Pathogenicity}

Zoospore suspensions were collected from strain LT1534 grown on $10 \%$ V8 juice agar medium containing NFD and inoculation assays were performed on etiolated C. annuum L. seedlings. As shown in Figure 5A, the hypocotyls of the etiolated seedlings inoculated with strain LT1534 zoospores showed typical disease symptoms and water-soaked lesions at $3 \mathrm{dpi}$. In contrast, NFDtreated strain LT1534 produced almost no lesions or very small lesions which did not expand beyond the inoculation site 
A

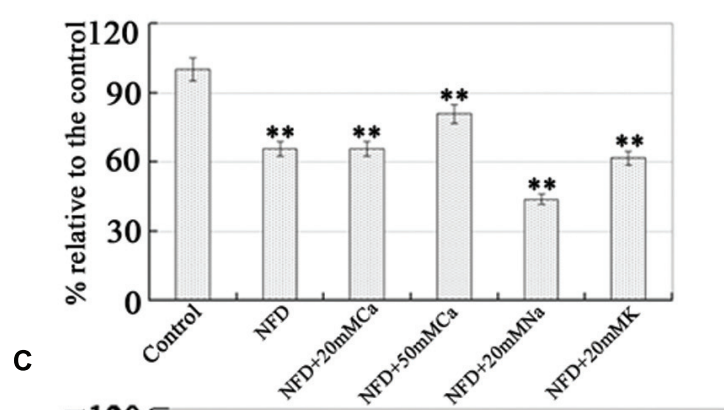

B

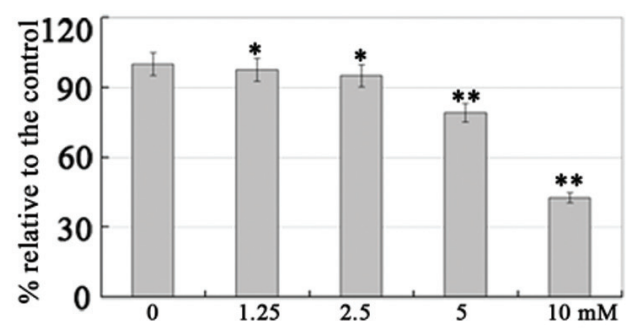

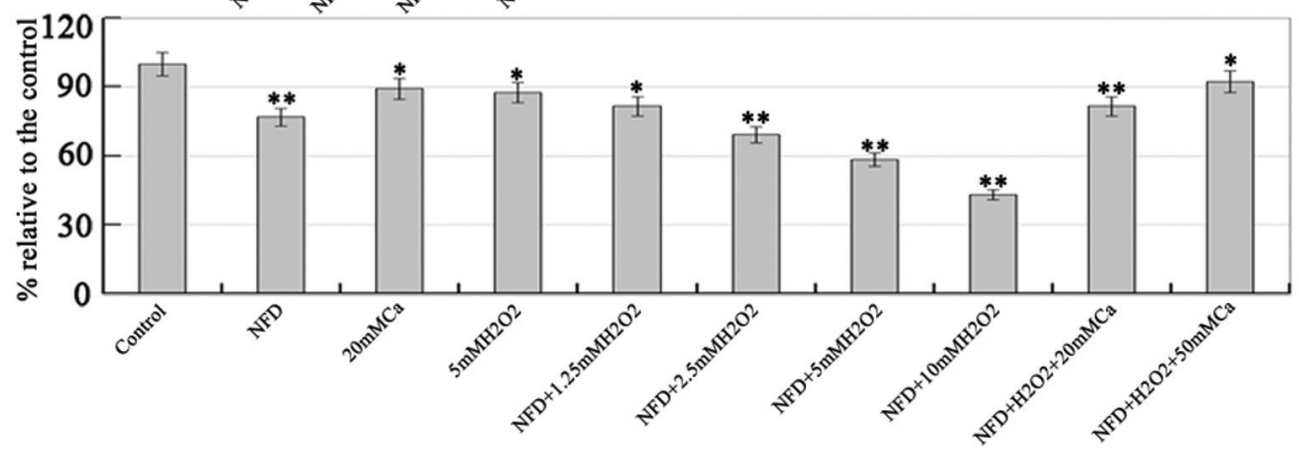

FIGURE 4 | Effects of $\mathbf{C a C l}_{2}$ and $\mathbf{H}_{\mathbf{2}} \mathbf{O}_{\mathbf{2}}$ on NFD-induced growth inhibition. (A) Extracellular calcium rescued NFD-inhibited mycelial growth. Mycelial was grown on $10 \%$ V8 juice agar medium containing $0.5 \mu \mathrm{M} \mathrm{NFD}$ (Control), $0.5 \mu \mathrm{M} \mathrm{NFD+20} \mathrm{mM} \mathrm{CaCl}, 0.5 \mu \mathrm{M} \mathrm{NFD}+50$ mM CaCl $2,0.5 \mu \mathrm{M} \mathrm{NFD}+20 \mathrm{mM} \mathrm{NaCl}$, and $0.5 \mu \mathrm{M} \mathrm{NFD}+20 \mathrm{mM} \mathrm{KCl}$. (B) Effect of $\mathrm{H}_{2} \mathrm{O}_{2}$ on $\mathrm{P}$. capsici mycelial growth. Mycelial was grown on $10 \%$ V8 juice agar medium containing $0,1.25,2.5$, 5, and $10 \mathrm{mM} \mathrm{H}_{2} \mathrm{O}_{2}$. (C) Effect of NFD on mycelial growth of $P$. capsici under various concentrations of $\mathrm{H}_{2} \mathrm{O}_{2}$. Mycelial was grown on $10 \%$ V8 juice agar medium containing $0.5 \mu \mathrm{M} N F D, 20 \mathrm{mM} \mathrm{CaCl}_{2}, 5 \mathrm{mM} \mathrm{H}_{2} \mathrm{O}_{2}, 0.5 \mu \mathrm{M} \mathrm{NFD}+1.25 \mathrm{mM} \mathrm{H}_{2} \mathrm{O}_{2}, 0.5 \mu \mathrm{M} \mathrm{NFD}+2.5 \mathrm{mM} \mathrm{H}_{2} \mathrm{O}_{2}, 0.5 \mu \mathrm{M} \mathrm{NFD}+5 \mathrm{mM} \mathrm{H} \mathrm{O}_{2}, 0.5 \mu \mathrm{M} \mathrm{NFD}+10 \mathrm{mM}$ $\mathrm{H}_{2} \mathrm{O}_{2}, 0.5 \mu \mathrm{M} \mathrm{NFD}+10 \mathrm{mM} \mathrm{H}_{2} \mathrm{O}_{2}+20 \mathrm{mM} \mathrm{CaCl}_{2}$, and $0.5 \mu \mathrm{M} \mathrm{NFD}+10 \mathrm{mM} \mathrm{H}_{2} \mathrm{O}_{2}+50 \mathrm{mM} \mathrm{CaCl}_{2}$. The mycelial colonies were 5 days old and radial growth (mm) was assessed by measuring the distance from the edge of the inoculum plug to the advancing margin of the colony. The assays were repeated three times; $n=5$ for each assay. Different letters above bars indicate statistical differences ${ }^{* *} P<0.01$ and $* P<0.05$, according to Dunnett's test).

(Figure 5A). To determine whether the pathogenicity defect was associated with the expression of pathogenicity-related genes during infection by $P$. capsici, we analyzed the relative expression ratios of the pectate lyase PcPL16 and laccase PcLAC2 genes. As shown in Figures 5B,C, the expression levels of PcPL16 and PCLAC2 were markedly higher in mycelia grown on V8 medium. In contrast, the expression levels of PcPL16 and PcLAC2 in the NFD-treated mycelia were significantly lower. Furthermore, the addition of calcium rescued the virulence and expression of PcPL16 and PcLAC2 to the levels observed in V8 medium. These results suggest that NFD inhibited the virulence and expression of pathogenicity-related genes in $P$. capsici.

\section{DISCUSSION}

Calcium efflux is involved in the fungicide CA-induced inhibition of P. capsici (Hu et al., 2013). The antifungal protein PAF from Penicillium chrysogenum has been used to control disease by increasing cytosolic free $\mathrm{Ca}^{2+}$, which is involved in hyphal tip growth, hyphal branching, sporulation, spore germination, different infection structure formation, circadian clocks, and responses to environment stimuli including osmotic stress, heat shock, mechanical stimulations, and oxidative stresses. Calcium channels allow the passive flow of $\mathrm{Ca}^{2+}$ across cell membranes into the cytosol. Voltage-gated $\mathrm{Ca}^{2+}$ channel blockers can inhibit the growth of fungal pathogens (Binder et al., 2010), but little is known about the effect of $\mathrm{Ca}^{2+}$ homeostasis on mycelial growth, sporulation, and virulence of oomycetes. NFD is the prototype calcium channel blocker of the dihydropyridine class, and the half-life of capsule and tablet are 2 and $11 \mathrm{~h}$ for the management of hypertension and angina pectoris (Toal, 2004). Previous studies have shown that NFD can potentiate cardiopulmonary baroreflex control of sympathetic nerve activity (Ferguson and Hayes, 1989), inhibit contractions in the body of the human esophagus (Richter et al., 1985) and decrease lymphocyte blastogenesis, IL2 production and NK activity in healthy humans (Morgano et al., 1990). In the present study, we first explored the effects of two well-known calcium channel blockers, VP and NFD, on mycelial growth and sporulation. As shown in Figure 2, NFD, but not VP, inhibited mycelial growth and sporulation of $P$. capsici strain LT1534 significantly. Meanwhile, we also found that $2 \mu \mathrm{M}$ NFD inhibited mycelial growth of Fujian and Jiangsu $P$. capsici strains significantly (Supplementary Figure S1), suggesting that NFD can inhibit mycelial growth of $P$. capsici. Lange and Peiter (2016) have shown that NFD drastically reduced colony growth in the filamentous fungal pathogen Colletotrichum graminicola, as observed before 


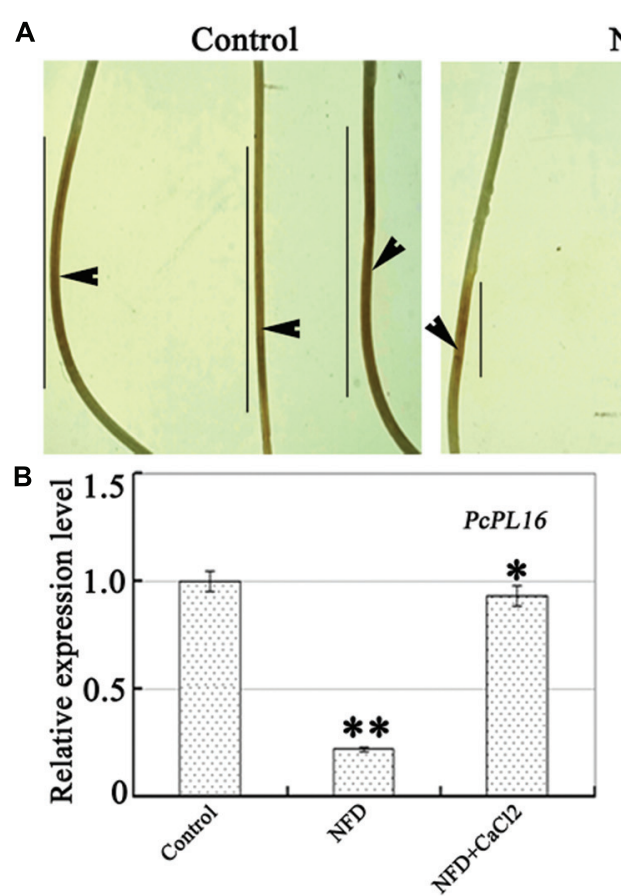

NFD

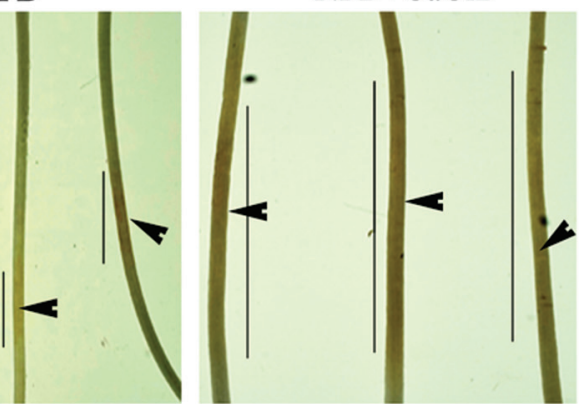

C

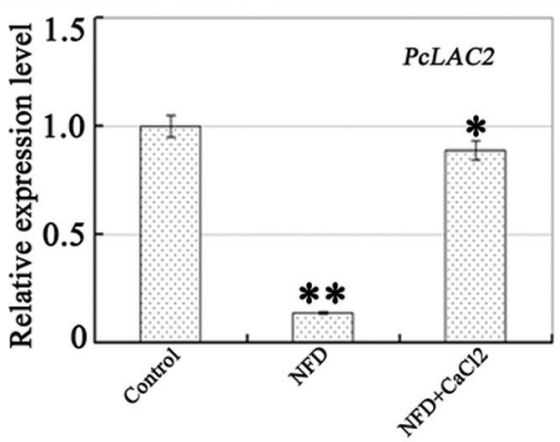

FIGURE 5 | Effect of NFD on $\boldsymbol{P}$. capsici virulence and expression of genes involved in pathogenicity. (A) Pathogenicity assays were performed on etiolated pepper seedlings. Etiolated pepper seedlings (C. annuum L. CV. yanshan01, CM334, and ECW) were inoculated with freshly prepared zoospores ( 100 in $10 \mathrm{~mL}$ ). Images were taken after $48 \mathrm{~h}$, and the experiments were repeated at least three times. Arrows indicate the inoculation site and lines indicate the lesion size. (B,C) Relative transcription levels of defense-related genes PCPL16 and PCLAC2 in NFD-treated mycelia. Transcription of the P. capsici ITS region in mycelia was used as a reference, which was set to a value of 1 . Error bars indicate the standard error. The experiments were repeated three times, together with at least three independent repetitions of the biological experiments. Values are means \pm SE $(n=6)$. Different letters above bars indicate statistical differences $(* * P<0.01$ and $* P<0.05$, according to Dunnett's test).

in Fusarium graminearum, and the affected growth to a much larger extent than external $\mathrm{Ca}^{2+}$ chelation; meanwhile, Scherp et al. (2001) also have shown that NFD is capable of stimulating the callose deposition in cells undergoing cytokinesis in Riella helicophylla and Arabidopsis thaliana, suggesting that NFD can be used in the crop protection. Extracellular calcium rescued NFDinhibited mycelial growth (Figure 4A), suggesting that NFDregulated calcium uptake is significantly beneficial for hyphal growth in $P$. capsici. In addition, NFD increased $P$. capsici sensitivity to $\mathrm{H}_{2} \mathrm{O}_{2}$ in a calcium-dependent manner (Figure 4C). Furthermore, oxidative stress alters calcium signaling, and calcium homeostasis and signaling is linked to pathogenesis (Hallen and Trail, 2008; Liu et al., 2015a).

The $\mathrm{Ca}^{2+}$ influx channels $\mathrm{Cch} 1$ and Mid1 in S. cerevisiae allow the passive flow of $\mathrm{Ca}^{2+}$ across cell membranes into the cytosol (Harren and Tudzynski, 2013), and the Cch1-Mid1 complex in Aspergillus fumigatus mediates the specific influx of $\mathrm{Ca}^{2+}$; calcium uptake impacts conidiation, vegetative growth, and polarity (Jiang et al., 2014). In the present study, we analyzed the effects of VP and NFD on mycelial growth and sporulation of $P$. capsici, and showed that VP functions in a mechanism that differs from that of NFD. In fact, NFD and VP use different binding sites in the cell wall (Nakayama and Kanaoka, 1996), and NFD and VP are members of the chemically unrelated classes of L-type blockers, dihydropyridines and phenylalkylamines, respectively. In addition, different inhibitory effects of three L-type calcium blockers (diltiazem, VP, and NFD) on ADPand collagen-induced platelet aggregation of human and rabbit platelets have been reported (Toque et al., 2008). In fact, the bioavailabilities of diltiazem, NFD, and VP differ with ranges of $40-50 \%, 40-50 \%$, and $10-30 \%$, respectively (Echizen and Eichelbaum, 1986).

Previous studies have suggested that HACS is involved in the oxidative stress response, and the calcium channel blocker VP inhibits the oxidative stress response in C. albicans ( $\mathrm{Yu}$ et al., 2014). In addition, deletion of three HACS regulator-encoding genes Cch1, Mid1, and Ecm 7 results in increased sensitivity to oxidative stress and decreased expression of several oxidative stress response genes (Ding et al., 2013). In the present study, NFD increased the sensitivity of $P$. capsici to $\mathrm{H}_{2} \mathrm{O}_{2}$ in a calciumdependent manner, suggesting that $P$. capsici treated with $\mathrm{H}_{2} \mathrm{O}_{2}$ and NFD encounters more severe oxidative stress than with $\mathrm{H}_{2} \mathrm{O}_{2}$ treatment alone. However, $50 \mathrm{mM}$ extracellular calcium rescued NFD-reduced mycelial growth under oxidative stress, suggesting that NFD inhibits mycelial growth under oxidative stress by disrupting calcium fluctuation.

In the present study, NFD-treated $P$. capsici produced very small lesions which showed no expansion beyond the inoculation site; in contrast, treatment with $\mathrm{NFD}$ and $\mathrm{CaCl}_{2}$ showed typical disease symptoms (Figure 5A). In fungi, the changed 
pathogenicity may be due to infection-related enzymes and effector-related protein secretion. During infection, diverse cell wall-degrading enzymes (e.g., pectinase) can be produced on the infection sites by Phytophthora spp. Pectinases degrade pectin, which is a major component of the primary cell wall and middle lamella of plants. Recent studies of the biological function of fungal laccases suggest that this enzyme plays an important role in fungal morphogenesis and fungal virulence (Li et al., 2013). In P. capsici, pectate lyase and laccase activities are important for successful infection during plantpathogen interactions (Feng and Li, 2014; Fu et al., 2015). Laccases, which served as blue copper oxidases, catalyze the one-electron oxidation (e.g., aromatic amines and phenolics) and other electron-rich substrates; there also has a reduction of $\mathrm{O}_{2}$ to $\mathrm{H}_{2} \mathrm{O}$ concomitantly. In the present study, the expression levels of laccase PCLAC2- and pectate lyase PCPL16-encoding genes were reduced significantly by $35-50 \%$ in NFD- and $\mathrm{H}_{2} \mathrm{O}_{2}$-treated $P$. capsici. In fact, Bacillus subtilis pectate lyase is in a complex with calcium (Pickersgill et al., 1994) and Rhizoctonia solani laccase activity is induced by $\mathrm{CaCl}_{2}$ (Crowe and Olsson, 2001). The promoter regions of laccase genes have several putative cis-acting elements such as xenobioticresponsive, metal-responsive, and stress-responsive elements. In addition, effector proteins function not only as toxins to induce plant cell death, but also to enable pathogens to suppress or evade plant defense responses. Necrosis-inducing NLP proteins have been reported to contribute strong virulence during infection by $P$. capsici (Feng et al., 2014). In our study, NFD treatment alone had no obvious effect on the expression of PCLAC2 and PcPL16. Successful rescue by $\mathrm{CaCl}_{2}$ suggested that NFD-inhibited $\mathrm{Ca}^{2+}$ absorption is important for virulence. Therefore, plants can respond to pathogenic fungi or oomycete infection by rapidly producing ROS using membrane-bound NADPH oxidases or secreted peroxidases and amine oxidases, as part of the general pathogen-associated molecular pattern (PAMP)-triggered immunity or more specific effector-triggered immunity responses (Latijnhouwers et al., 2003).

In the present study, our results showed that the calcium channel blocker NFD has an inhibitory effect on $P$. capsici calcium fluctuation under oxidative stress and impacts the oxidative stress response, confirming a connection between

\section{REFERENCES}

Binder, U., Chu, M., Read, N. D., and Marx, F. (2010). The antifungal activity of the Penicillium chrysogenum protein PAF disrupts calcium homeostasis in Neurospora crassa. Eukaryot. Cell 9, 1374-1382. doi: 10.1128/EC.00 050-10

Bormann, J., and Tudzynski, P. (2009). Deletion of Mid1, a putative stretchactivated calcium channel in Claviceps purpurea, affects vegetative growth, cell wall synthesis and virulence. Microbiology 155, 3922-3933. doi: 10.1099/mic.0.030825-0

Breeuwer, P., Drocourt, J. L., Bunschoten, N., Zwietering, M. H., Rombouts, F. M., and Abee, T. (1995). Characterization of uptake and hydrolysis of fluorescein diacetate and carboxyfluorescein diacetate by intracellular esterases in Saccharomyces cerevisiae, which result in accumulation of fluorescent product. Appl. Environ. Microbiol. 61, 1614-1619. calcium signaling and the oxidative stress response in this pathogen. Interestingly, Scherp et al. (2001) have shown that NFD is capable of stimulating the callose deposition in cells undergoing cytokinesis in Riella helicophylla and Arabidopsis thaliana, and Larkindale and Knight (2002) also have shown that NFD increases heat stress in Arabidopsis thaliana, suggesting that there has no phytotoxicity in NFD application. Therefore, calcium channels may be potential targets for therapy to enhance the efficacy of oxidative stress against $P$. capsici-related infections and NFD can be used to the crop protection safely.

\section{AUTHOR CONTRIBUTIONS}

PL, QW, and QC designed the study. JG, XD, YJ, BL, and GC performed the experiments. All authors analyzed the data. PL, QW, and QC wrote the article. All authors contributed to the research and manuscript and read and approved the final version of the manuscript. All authors agree to be accountable for all aspects of the work.

\section{ACKNOWLEDGMENTS}

This work was supported by the Provincial Public Project in Fujian Province (Grant No. 2014R1024-9); National Natural Science Foundation of China (Grant No. 31401701); Natural Science Foundation of Fujian Province (Grant No. 2014J05037 and 2014J01109); Hundred Young Talents of FAAS (Grant No. YC2015-3).

\section{SUPPLEMENTARY MATERIAL}

The Supplementary Material for this article can be found online at: http://journal.frontiersin.org/article/10.3389/fmicb. 2016.01236

FIGURE S1 | Effects of nifedipine (NFD) on mycelial growth of Fujian and Jiangsu $P$. capsici strains. Analysis of the inhibition of $P$. capsici strains PCZZ-10 and PCNJ9 mycelium growth at $2 \mu \mathrm{M}$ NFD. The mycelial colonies were 5 days old and radial growth $(\mathrm{mm})$ was assessed by measuring the distance from the edge of the inoculum plug to the advancing margin of the colony.

Cavinder, B., Hamam, A., Lew, R. R., and Trail, F. (2011). Mid1, a mechanosensitive calcium ion channel, affects growth, development, and ascospore discharge in the filamentous fungus Gibberella zeae. Eukaryot. Cell 10, 832-841. doi: 10.1128/EC.00235-10

Crowe, J. D., and Olsson, S. (2001). Induction of laccase activity in Rhizoctonia solani by antagonistic Pseudomonas fluorescens strains and a range of chemical treatments. Appl. Environ. Microbiol. 67, 2088-2094. doi: 10.1128/AEM.67.5.2088-2094.2001

Ding, X., Yu, Q., Xu, N., Wang, Y., Cheng, X., Qian, K., et al. (2013). Ecm7, a regulator of HACS, functions in calcium homeostasis maintenance, oxidative stress response and hyphal development in Candida albicans. Fungal Genet. Biol. 57, 23-32. doi: 10.1016/j.fgb.2013.05.010

Echizen, H., and Eichelbaum, M. (1986). Clinical pharmacokinetics of verapamil, nifedipine and diltiazem. Clin. Pharmacokinet. 11, 425-449. doi: 10.2165/00003088-198611060-00002 
Ermak, G., and Davies, K. J. (2002). Calcium and oxidative stress: from cell signaling to cell death. Mol. Immunol. 38, 713-721. doi: 10.1016/S01615890(01)00108-0

Feng, B. Z., and Li, P. (2014). Cloning, characterization and expression of a novel laccase gene Pclac2 from Phytophthora capsici. Braz. J. Microbiol. 45, 351-358. doi: 10.1590/S1517-83822014005000021

Feng, B. Z., Zhu, X. P., Fu, L., Lv, R.-F., Storey, D., Tooley, P., et al. (2014). Characterization of necrosis-inducing NLP proteins in Phytophthora capsici. BMC Plant Biol. 14:126. doi: 10.1186/1471-2229-14-126

Ferguson, D., and Hayes, D. (1989). Nifedipine potentiates cardiopulmonary baroreflex control of sympathetic nerve activity in healthy humans. Direct evidence from microneurographic studies. Circulation 80, 285-298. doi: 10.1161/01.CIR.80.2.285

Fu, L., Zhu, C., Ding, X., Yang, X., Morris, D., Tyler, B. M., et al. (2015). Characterization of cell death-inducing members of the pectate lyase gene family in Phytophthora capsici and their contributions to infection of pepper. Mol. Plant-Microbe Interact. 28, 766-775. doi: 10.1094/MPMI-11-14-0352-R

Gonçalves, A. P., Monteiro, J., Lucchi, C., Kowbel, D. J., Cordeiro, J. M., Correiade-Sá, P., et al. (2014). Extracellular calcium triggers unique transcriptional programs and modulates staurosporine-induced cell death in Neurospora crassa. Microbial. Cell 1, 289-302. doi: 10.15698/mic2014.09.165

Gordeeva, A., Zvyagilskaya, R., and Labas, Y. A. (2003). Cross-talk between reactive oxygen species and calcium in living cells. Biochemistry (Mosc). 68, 1077-1080. doi: $10.1023 / \mathrm{A}: 1026398310003$

Hallen, H. E., and Trail, F. (2008). The L-type calcium ion channel cch1 affects ascospore discharge and mycelial growth in the filamentous fungus Gibberella zeae (anamorph Fusarium graminearum). Eukaryot. cell 7, 415-424. doi: 10.1128/EC.00248-07

Harren, K., and Tudzynski, B. (2013). Cch1 and Mid1 are functionally required for vegetative growth under low-calcium conditions in the phytopathogenic ascomycete Botrytis cinerea. Eukaryot. cell 12, 712-724. doi: 10.1128/EC. 00338-12

Hockerman, G., Dilmac, N., Scheuer, T., and Catterall, W. (2000). Molecular determinants of diltiazem block in domains IIIS6 and IVS6 of L-type $\mathrm{Ca}(2+)$ channels. Mol. Pharmacol. 58, 1264-1270. doi: 10.1124/mol.58.6.1264

Hu, L., Wang, D., Liu, L., Chen, J., Xue, Y., and Shi, Z. (2013). Ca (2+) efflux is involved in cinnamaldehyde-induced growth inhibition of Phytophthora capsici. PLoS ONE 8:e76264. doi: 10.1371/journal.pone.0076264

Iribarren, M. J., Pascuan, C., Soto, G., and Ayub, N. D. (2015). Genetic analysis of environmental strains of the plant pathogen Phytophthora capsici reveals heterogeneous repertoire of effectors and possible effector evolution via genomic island. FEMS Microbiol. Lett. 362:fnv189. doi: 10.1093/femsle/ fnv189

Jackson, K., Yin, J., and Ji, P. (2012). Sensitivity of Phytophthora capsici on vegetable crops in Georgia to mandipropamid, dimethomorph and cyazofamid. Plant Dis. 96, 1337-1342. doi: 10.1094/PDIS-12-11-1082-RE

Jiang, H., Shen, Y., Liu, W., and Lu, L. (2014). Deletion of the putative stretchactivated ion channel Mid1 is hypervirulent in Aspergillus fumigatus. Fungal Genet. Biol. 62, 62-70. doi: 10.1016/j.fgb.2013.11.003

Juvvadi, P. R., Muñoz, A., Lamoth, F., Soderblom, E. J., Moseley, M. A., Read, N. D., et al. (2015). Calcium-mediated induction of paradoxical growth following caspofungin treatment is associated with calcineurin activation and phosphorylation in Aspergillus fumigatus. Antimicrob. Agents Chemother. 59, 4946-4955. doi: 10.1128/AAC.00263-15

Kraus, P. R., and Heitman, J. (2003). Coping with stress: calmodulin and calcineurin in model and pathogenic fungi. Biochem. Biophys. Res. Commun. 311, 1151-1157. doi: 10.1016/S0006-291X(03)01528-6

Lamour, K. H., Mudge, J., Gobena, D., Hurtado-Gonzales, O. P., Schmutz, J., Kuo, A., et al. (2012). Genome sequencing and mapping reveal loss of heterozygosity as a mechanism for rapid adaptation in the vegetable pathogen Phytophthora capsici. Mol. Plant-Microbe Interact. 25, 1350-1360. doi: 10.1094/MPMI-02-12-0028-R

Lange, M., and Peiter, E. (2016). Cytosolic free calcium dynamics as related to hyphal and colony growth in the filamentous fungal pathogen Colletotrichum graminicola. Fungal Genet. Biol. 91, 55-65. doi: 10.1016/j.fgb.2016.04.001

Larkindale, J., and Knight, M. R. (2002). Protection against heat stress-induced oxidative damage in Arabidopsis involves calcium, abscisic acid, ethylene, and salicylic acid. Plant Physiol. 128, 682-695. doi: 10.1104/pp.010320
Latijnhouwers, M., de Wit, P. J., and Govers, F. (2003). Oomycetes and fungi: similar weaponry to attack plants. Trends Microbiol. 11, 462-469. doi: 10.1016/j.tim.2003.08.002

Li, D., Zhao, Z., Huang, Y., Lu, Z., Yao, M., Hao, Y., et al. (2013). PsVPS1, a dynamin-related protein, is involved in cyst germination and soybean infection of Phytophthora sojae. PLoS ONE 8:e58623. doi: 10.1371/journal.pone.0058623

Liu, P., Li, B., Lin, M., Chen, G., Ding, X., Weng, Q., et al. (2016). Phosphite-induced reactive oxygen species production and ethylene and $\mathrm{ABA}$ biosynthesis, mediate the control of Phytophthora capsici in pepper (Capsicum annuum). Funct. Plant Biol. 43, 563-574. doi: 10.1071/FP16006

Liu, S., Hou, Y., Liu, W., Lu, C., Wang, W., and Sun, S. (2015a). Components of the calcium-calcineurin signaling pathway in fungal cells and their potential as antifungal targets. Eukaryot. cell 14, 324-334. doi: 10.1128/EC.00271-14

Liu, Z. Q., Qiu, A. L., Shi, L. P., Cai, J. S., Huang, X. Y., Yang, S., et al. (2015b). SRC21 is required in PcINF1-induced pepper immunity by acting as an interacting partner of PcINF1. J. Exp. Bot. 66, 3683-3698. doi: 10.1093/jxb/erv161

Martin, D. C., Kim, H., Mackin, N., Maldonado-Báez, L., Evangelista, C., Beaudry, V., et al. (2011). New regulators of a high-affinity Ca2+ influx system revealed through a genome-wide screen in yeast. J. Biol. Chem. 286, 10744-10754. doi: 10.1074/jbc.m110.177451

Morgano, A., Pierri, I., Stagnaro, R., Setti, M., Puppo, F., and Indiveri, F. (1990). Decreased lymphocyte blastogenesis, IL2 production and NK activity following nifedipine administration to healthy humans. Eur. J. Clin. Pharmacol. 39, 545-550. doi: 10.1007/BF00316092

Nakayama, H., and Kanaoka, Y. (1996). Chemical identification of binding sites for calcium channel antagonists. Heterocycles 42, 901-909. doi: 10.3987/REV95-SR4

Nguemo, F., Fleischmann, B. K., Gupta, M. K., Šarić, T., Malan, D., Liang, H., et al. (2013). The L-type Ca 2+ channels blocker nifedipine represses mesodermal fate determination in murine embryonic stem cells. PLOS ONE 8:e53407. doi: 10.1371/journal.pone.0053407

Pickersgill, R., Jenkins, J., Harris, G., Nasser, W., and Robert-Baudouy, J. (1994). The structure of Bacillus subtilis pectate lyase in complex with calcium. Nat. Struct. Mol. Biol. 1, 717-723. doi: 10.1038/nsb1094-717

Puigpinós, J., Casas, C., and Herrero, E. (2015). Altered intracellular calcium homeostasis and endoplasmic reticulum redox state in Saccharomyces cerevisiae cells lacking Grx6 glutaredoxin. Mol. Biol. Cell. 26, 104-116. doi: 10.1091/mbc.E14-06-1137

Richter, J. E., Dalton, C. B., Buice, R. G., and Castell, D. O. (1985). Nifedipine: a potent inhibitor of contractions in the body of the human esophagus: studies in healthy volunteers and patients with the nutcracker esophagus. Gastroenterology 89, 549-554. doi: 10.1016/0016-5085(85)90450-0

Scherp, P., Grotha, R., and Kutschera, U. (2001). Deposition of cytokinesis-related callose in Riella helicophylla and Arabidopsis thaliana. Effects of photolytically altered nifedipine. Plant Biol. 3, 311-318. doi: 10.1055/s-2001-16458

Sheng, Y., Wang, Y., Meijer, H. J., Yang, X., Hua, C., Ye, W., et al. (2015). The heat shock transcription factor PsHSF1 of Phytophthora sojae is required for oxidative stress tolerance and detoxifying the plant oxidative burst. Environ. Microbiol. 17, 1351-1364. doi: 10.1111/1462-2920.12609

Shreaz, S., Sheikh, R., Rimple, B., Hashmi, A., Nikhat, M., Khan, L. A., et al. (2010). Anticandidal activity of cinnamaldehyde, its ligand and $\mathrm{Ni}(\mathrm{II})$ complex: effect of increase in ring and side chain. Microb. Pathog. 49, 75-82. doi: 10.1016/j.micpath.2010.03.013

Stam, R., Motion, G., Boevink, P. C., and Huitema, E. (2013). A conserved oomycete CRN effector targets and modulates tomato TCP14-2 to enhance virulence. BioRxiv doi: 10.1101/001248

Sugimoto, T., Aino, M., Sugimoto, M., and Watanabe, K. (2005). Reduction of Phytophthora stem rot disease on soybeans by the application of $\mathrm{CaCl} 2$ and $\mathrm{Ca}$ (NO3) 2. J. Phytopathol. 153, 536-543. doi: 10.1111/j.1439-0434.2005. 01016.x

Sugimoto, T., Watanabe, K., Yoshida, S., Aino, M., Furiki, M., Shiono, M., et al. (2010). Field application of calcium to reduce Phytophthora stem rot of soybean, and calcium distribution in plants. Plant Dis. 94, 812-819. doi: 10.1094/PDIS94-7-0812

Teng, J., Goto, R., Iida, K., Kojima, I., and Iida, H. (2008). Ion-channel blocker sensitivity of voltage-gated calcium-channel homologue Cch1 in Saccharomyces cerevisiae. Microbiology 154 (Pt. 12), 3775-3781. doi: 10.1099/mic.0.2008/021089-0 
Toal, C. B. (2004). Formulation dependent pharmacokinetics-does the dosage form matter for nifedipine? J. Cardiovas. Pharmacol. 44, 82-86. doi: 10.1097/00005344-200407000-00011

Toque, H., Teixeira, C., Priviero, F., Morganti, R., Antunes, E., and De Nucci, G. (2008). Vardenafil, but not sildenafil or tadalafil, has calcium-channel blocking activity in rabbit isolated pulmonary artery and human washed platelets. $\mathrm{Br}$. J. Pharmacol. 154, 787-796. doi: 10.1038/bjp.2008.141

Vu, K., Bautos, J. M., and Gelli, A. (2015). The Cch1-Mid1 high-affinity calcium channel contributes to the virulence of Cryptococcus neoformans by mitigating oxidative stress. Eukaryot. cell 14, 1135-1143. doi: 10.1128/EC.00100-15

Wang, S., Cao, J., Liu, X., Hu, H., Shi, J., Zhang, S., et al. (2012). Putative calcium channels CchA and MidA play the important roles in conidiation, hyphal polarity and cell wall components in Aspergillus nidulans. PLoS ONE 7:e46564. doi: 10.1371/journal.pone.0046564

Wang, S., Chen, P., and Chang, S. (2005). Antifungal activities of essential oils and their constituents from indigenous cinnamon (Cinnamomum osmophloeum) leaves against wood decay fungi. Bioresour. Technol. 96, 813-818. doi: 10.1016/j.biortech.2004.07.010
Yu, Q., Wang,H., Cheng, X., Xu, N., Ding, X., Xing, L., et al. (2012). Roles of Cch1 and Mid1 in morphogenesis, oxidative stress response and virulence in Candida albicans. Mycopathologia 174, 359-369. doi: 10.1007/s11046-012-9569-0

Yu, Q., Xiao, C., Zhang, K., Jia, C., Ding, X., Zhang, B., et al. (2014). The calcium channel blocker verapamil inhibits oxidative stress response in Candida albicans. Mycopathologia 177, 167-177. doi: 10.1007/s11046-014-9735-7

Conflict of Interest Statement: The authors declare that the research was conducted in the absence of any commercial or financial relationships that could be construed as a potential conflict of interest.

Copyright (c) 2016 Liu, Gong, Ding, Jiang, Chen, Li, Weng and Chen. This is an open-access article distributed under the terms of the Creative Commons Attribution License (CC BY). The use, distribution or reproduction in other forums is permitted, provided the original author(s) or licensor are credited and that the original publication in this journal is cited, in accordance with accepted academic practice. No use, distribution or reproduction is permitted which does not comply with these terms. 